\title{
Inhibition Kinetics of Agaricus bisporus (J.E. Lange) Imbach Polyphenol Oxidase
}

\author{
Hicham Gouzi $^{1, *}$, Thibaud Coradin ${ }^{1}$, Estrella Núñez Delicado ${ }^{2}$ M. Ümit Ünal ${ }^{3}$ and Abdelhafid Benmansour ${ }^{4}$ \\ ${ }^{1}$ UPMC-P6; CNRS, Chimie de la Matière Condensée de Paris, Collège de France, 11, place Marcelin-Berthelot, 75231 \\ Paris cedex 05, France \\ ${ }^{2}$ Department of Food Science and Technology, San Antonio Catholic University of Murcia, Avda, De Los Jerónimos s/n, \\ 30107 Guadalupe, Murcia, Spain \\ ${ }^{3}$ Department of Food Engineering, Faculty of Agriculture, University of Cukurova, 01330 Adana, Turkey \\ ${ }^{4}$ Department of Biology, Faculty of Science, Abou Bekr Belkaid University, Laboratory for Naturals Products Research, \\ Tlemcen 13000, Algeria
}

\begin{abstract}
This paper reports the inhibition kinetics of mushroom (Agaricus bisporus; J.E. Lange) polyphenol oxidase (PPO) with benzoic acid, sodium azide and sodium fluoride as inhibitors, and pyrocatechol as substrate. Mushroom PPO was significantly inhibited by all of the tested inhibitors.

Diphenolase activity of mushroom PPO exhibited the competitive-type inhibition with benzoic acid as an inhibitor; the inhibition constant $K_{\mathrm{I}}$ was found to be $0.046 \mathrm{mM}$. The inhibition by sodium azide was of the mixed-I type, with a $K_{\mathrm{I}}$ of 1.39 $\mathrm{mM}$ and $K_{\mathrm{IS}}$ of $3.12 \mathrm{mM}$. A partial mixed-type inhibition pattern was obtained with sodium fluoride, with a $K_{\mathrm{I}}$ of $148.97 \mathrm{mM}$ and a $K_{\mathrm{IS}}$ of $49.19 \mathrm{mM}$. The $\mathrm{IC}_{50}$ values were estimated to be $0.147,3.20$, and $123.94 \mathrm{mM}$ for benzoic acid, sodium azide, and sodium fluoride, respectively. Furthermore, benzoic acid was the most effective inhibitor because of its low $K_{\mathrm{I}}$ value. The results showed that the type of inhibition was dependent upon both the origin of the PPO and on the substrate.
\end{abstract}

Keywords: Agaricus bisporus, polyphenol oxidase, diphenolase, pyrocatechol, inhibition, kinetics.

\section{INTRODUCTION}

Mushroom Agaricus bisporus (J.E. Lange) Imbach is the most widely cultivated and consumed edible fungus worldwide. Mushrooms have a short shelf life compared with most fruits and vegetables. Intact mushrooms lose their commercial value within a few days due to senescence, water loss, microbial attack and browning [1].

Browning usually degrades the sensory properties of products because of the associated changes in colour, flavour and hardness. These changes shorten the products' shelf lives and decrease their nutritional and market values [2]. Enzymatic browning is caused mainly by the activity of polyphenol oxidase (EC 1.14.18.1; PPO) in the presence of oxygen [2]. Because of its involvement in this adverse browning effect, PPO has received considerable attention from researchers in the fields of plant physiology and food science [3].

PPO is widely distributed in nature and has been detected in most fruits and vegetables [4]. PPO is a copper-containing enzyme that is responsible for melanization in animals and browning in plants. The enzyme catalyzes two distinct reactions: the $o$-hydroxylation of monophenols to $o$-diphenols

\footnotetext{
*Address correspondence to this author at the Université Pierre et Marie Curie-Paris 6; CNRS, Chimie de la Matière Condensée de Paris, Collège de France, 11, place Marcelin-Berthelot, 75231 Paris cedex 05, France; Tel: +33-144-27-15-28; Fax: +33 1442714 43;

E-mail: hicham.gouzi@upmc.fr
}

(cresolase activity) (E.C 1.14.18.1) and the oxidation of $o$ diphenols to $o$-quinones (catecholase activity) (EC 1.10.3.2), which polymerize to form a brown, red or black pigment [5].

Mushroom PPO can also oxidize some triphenols when used as a substrate [6]. For example, oxidation of pyrogallol by PPO yields purpurogallin (o-hydroxyquinone) as well as additional undefined dark product(s); there is also a subsequent nonenzymatic conversion of purpurogallin to pigmented dimers, tetramers or polymers [7].

The control of PPO activity is of importance in preventing the synthesis of melanin in the browning of mushrooms and other vegetables and fruits [1-8]. In addition, PPO inhibitors have been used as depigmenting agents for the treatment or prevention of pigmentation disorders. Hence, PPO inhibitors are supposed to have broad applications in the medical and cosmetic industries [9]. In the food industry, PPO inhibitors could be used as preservatives for foods and beverages of plant origin. Furthermore, PPO is one of the most important key enzymes in the insect molting process, and thus the discovery of inhibitors of this enzyme may be important in the development of new alternatives for insect control [10].

The inhibition of PPO and prevention of enzymatic browning are often treated as one and the same subject. However, browning may be prevented not only by inactivating the enzyme but also by eliminating one of the two required substrates $\left(\mathrm{O}_{2}\right.$ and the phenolic substrate), or by reacting with the enzymatic products to prevent formation of the 
colored compounds, which are produced in secondary, nonenzymatic reaction steps [4].

PPO inhibitors fall into three groups: (i) small molecules or ions that bind to the copper centre in the active site, (ii) aromatic inhibitors that compete with phenolic substrates for binding to the active site, and (iii) compounds that reduce or oxidize copper ions [11].

PPO can be inhibited by chelating agents such as cyanide, carbon monoxide, sodium diethyl-dithiocarbamate (DIECA), tropolone, L-mimosine, 2-mercaptothiobenzothiazole, azide, potassium methyl xanthate, L-Ascorbic acid, 4-hexylresorcinol and EDTA $[1,4,12]$. Inorganic ions such as $\mathrm{Cu}^{2+}, \mathrm{Ca}^{2+}, \mathrm{Zn}^{2+}, \mathrm{Co}^{2+}, \mathrm{Ni}^{2+}, \mathrm{Mn}^{2+}, \mathrm{Ba}^{2+}, \mathrm{Mg}^{2+}, \mathrm{Hg}^{2+}$ and $\mathrm{Sn}^{2+}$, including halides, are also known to inhibit PPOs from many sources [13-15].

Potential PPO inhibitors from mushrooms, cherries, apples, pears, apricots and potatoes are primarily found in the form of aromatic acids, aromatic aldehydes, carboxylic acids, phloridzin dihydrate and some substituted cinnamic acids [8]. In addition, compounds that do not resemble the substrate structure but are slowly oxidised, such as 4nitrocatechol, $p$-nitrophenol and 4-chlorophenol, have been identified as competitive inhibitors of PPO [16]. Inhibition of PPO is also caused by reducing agents, among which sulphites, $\mathrm{SO}_{2}$, ascorbic acid, erythorbic acid and thiol-containing compounds are the most frequently studied [5]. Thiol compounds, including L-cysteine, glutathione, dithiothreitol, mercaptoethanol and thiourea, are effective inhibitors of many PPO systems including those found in apple, pear, Jerusalem artichoke tubers, cherimoya, banana, avocado and mushroom [11, 17, 18]. More recently, other plants have been found as a potential source of PPO inhibitors [19]. Among these isolated compounds, cuminaldehyde, oxyresveratrol, kaempferol, quercetin, morin, luteolin, anisaldehyde, kurarinone and gallic acid derivatives are the most potent PPO inhibitors [12]. Several published reports have characterized and evaluated the control of enzymatic browning in Agaricus bisporus. However, no published studies have evaluated inhibition of the diphenolase activity of mushroom PPO using pyrocatechol as a substrate.

The present study aimed to carry out a kinetic study of inhibition of the diphenolase activity of partially purified Agaricus bisporus PPO by benzoic acid, sodium azide, and sodium fluoride. The main goal of this work was to evaluate the kinetic parameters and inhibition constants for these reactions in order to characterize the system and investigate the mechanism of inhibition. The results of these studies are also compared to data obtained from other sources.

Finally, in an attempt to control browning of the mushroom, the inhibitory potency and $\mathrm{IC}_{50}$ values for various inhibitors of PPO activity were determined.

\section{MATERIALS AND METHODS}

\section{Materials}

PPO enzyme was obtained from the common commercially cultivated mushroom (Agaricus bisporus) bought fresh on the free market. Mushrooms were chosen to be white, fresh and as young as possible. The carpophores were cleaned and stored at $4{ }^{\circ} \mathrm{C}$ until they were used as the source for enzyme extraction.

Pyrocatechol was obtained from Fluka. All other chemicals and reagents were of analytical grade.

\section{Extraction and Purification of Mushroom PPO}

The extraction and partial purification of Agaricus bisporus (J.E. Lange) Imbach polyphenol oxidase have been given in our previous study [6].

\section{Measurement of PPO Activity}

PPO activity was determined by measuring the initial rate of quinone formation, as indicated by an increase in absorbance at $410 \mathrm{~nm}$ using pyrocatechol as substrate [20]. A Jenway spectrophotometer was employed throughout the investigation. Stock solution of pyrocatechol was prepared in $0.5 \mathrm{mM}$ ortho-phosphoric acid [20]. One unit of enzyme was defined as a change of one absorbance unit per min [20]. PPO activity was assayed in triplicate measurements and the corresponding mean values were plotted.

The sample cuvette contained $1.99 \mathrm{~mL}$ of substrate solution in $0.1 \mathrm{M}$ sodium phosphate buffer $(\mathrm{pH} 7.0)$ and $0.01 \mathrm{~mL}$ of the enzyme solution. The blank sample contained only 2 $\mathrm{mL}$ of substrate solution.

The reaction was initiated by the addition of enzymatic extract to the assay medium. The substrates, inhibitors and enzyme fraction were mixed after a pre-incubation period of $5 \mathrm{~min}$ at $25^{\circ} \mathrm{C}$. The initial rate was calculated from the slope of the absorbance-time curve [6]. Unless otherwise indicated, PPO was the last component added to the reaction mixture.

\section{Effects of Inhibitors}

To determine the effect of inhibitors (benzoic acid, sodium azide and sodium fluoride), PPO activity was measured in the standard reaction medium in the presence or absence of the stated concentration of inhibitor at varying concentrations of substrate ranging from $0.125-1 \mathrm{mM}$. PPO activities were measured at two constant inhibitor concentrations. Inhibition patterns were determined from double reciprocal plots of velocity versus initial substrate concentration for each inhibitor [5]. The inhibition constants were obtained from the second plots of the kinetic parameters against the inhibitor concentration, as previously described [21]. The inhibition constant $K_{\mathrm{I}}$ is a quantitative measure of inhibitor potency for reversible inhibitors. The effectiveness of inhibitors in our study is therefore expressed by $K_{\mathrm{I}}$, which is the reciprocal of the enzyme-inhibitor affinity. To determine the inhibitor concentration that reduced the enzyme activity by $50 \%\left(\mathrm{IC}_{50}\right)$, regression analysis graphs were drawn by using percent inhibition values by a statistical package programme on a computer. $\mathrm{IC}_{50}$ values were determined from a plot of residual activity against inhibitor concentration [22].

\section{Data Analysis}

Kinetic data analysis was carried out using linear regression fitting by application of the programs Table Curve $2 \mathrm{D}^{\mathrm{TM}}$ v2.03, Enzyme Kinetics Pro ${ }^{\mathrm{TM}}$ Version 2.36 and SigmaPlot 2004 for Windows Version 9.01. A linear regression method was used to determine whether the experimental data fit the 
inhibition equations. The linear regression coefficients are given in Table 1. The regression coefficient values, which were in the range 0.998-1.00, indicate that the experimental data fit the related inhibition equations.

\section{RESULTS AND DISCUSSION}

In this study, inhibition of mushroom PPO by benzoic acid, sodium azide, and sodium fluoride was investigated, while pyrocatechol was used as substrate. The prevention of enzymatic browning by a single inhibitor may involve a single mechanism of action or it may result from the interplay of two or more mechanisms of inhibitory action [5].

\section{Competitive Inhibition of Mushroom PPO Diphenol Oxidase Activity by Benzoic Acid}

Under the conditions used in the present investigation, oxidation of pyrocatechol by mushroom PPO followed Michaelis-Menten kinetics. Kinetic studies of the enzyme in the presence of benzoic acid are presented by the Lineweaver-Burk plot shown in Fig. (1). The inhibition behaviour of benzoic acid was shown to act competitively. The inhibitory character of benzoic acid is due to the presence of a benzene ring in its structure [23].

The plot of $1 / v_{\text {o }}$ versus $1 /[S]$ consisted of a family of straight lines with varying slopes that intersected one another along the $\mathrm{Y}$-axis. The values of $V_{\max }$ remained the same and the values of $K_{\mathrm{m}}$ increased with the concentration of the inhibitor, which indicates that benzoic acid acted as a competitive inhibitor of the mushroom PPO. Competitive inhibitors bind free enzyme and not the enzyme-substrate complex. The equilibrium constant for inhibitor binding with free enzyme, $K_{\mathrm{I}}$, was obtained from a plot of the apparent Michaelis-Menten constant $\left(K_{\mathrm{m}}\right)$ versus the concentration of the inhibitor. As seen from Table 1, the inhibitor constants $\left(K_{\mathrm{I}}\right)$ for benzoic acid using pyrocatechol as a substrate, was 0.046 $\mathrm{mM}$. Our results agree with those reported previously by Duckworth and Coleman [24]. Gouzi and Benmansour [6]

Table 1. Inhibition type, $\mathrm{K}_{\mathrm{I}}, \mathrm{K}_{\mathrm{IS}}$, and $\mathrm{IC}_{50}$ of Agaricus bisporus PPO with Pyrocatechol as Substrate

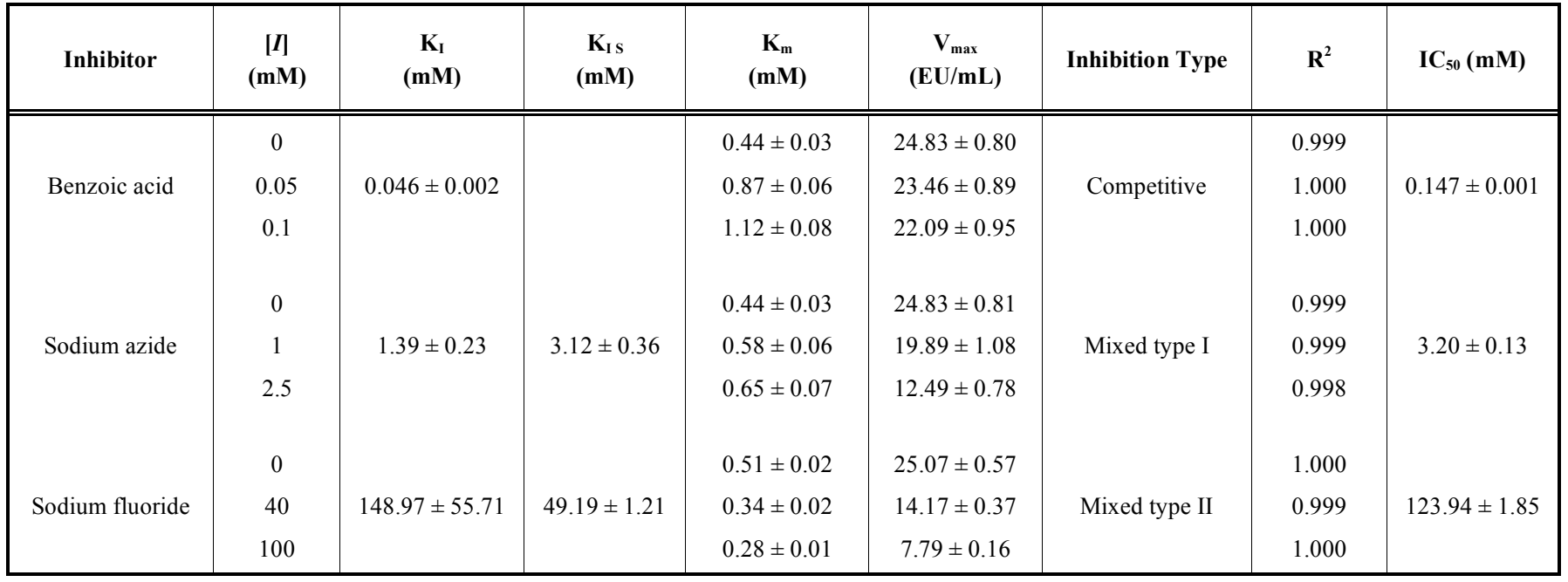

Each value represents the mean of three replicates \pm SD.

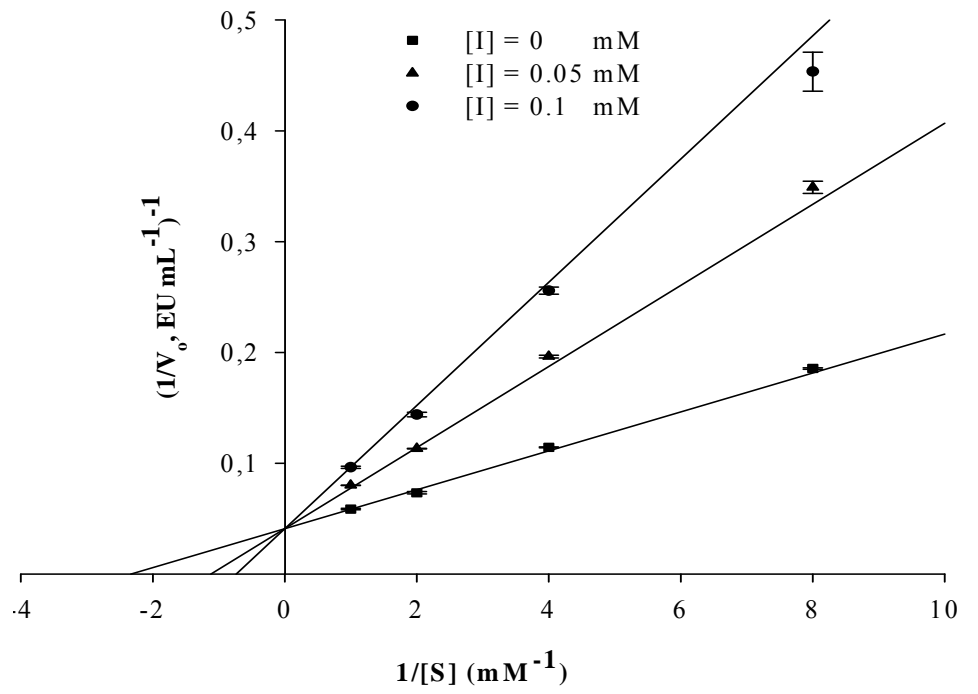

Fig. (1). Lineweaver-Burk plots for inhibition of PPO-mediated oxidation of pyrocatechol by benzoic acid. The concentrations of benzoic acid were $0(\boldsymbol{\bullet}), 0.05(\boldsymbol{\Delta})$, and $0.1 \mathrm{mM}(\bullet)$. Each value is expressed as the mean $\pm \mathrm{SE}$ of three trials. 
observed a competitive-type inhibition by benzoic acid for the triphenol oxidase activity of mushroom PPO using pyrogallol as substrate, with $K_{\mathrm{I}}$ value of $0.043 \mathrm{mM}$.

\section{Mixed-Type I Inhibition of Mushroom PPO Diphenol Oxidase Activity by Sodium Azide}

Under the experimental conditions used in this study, the oxidation of pyrocatechol by mushroom PPO followed Michaelis-Menten kinetics. In the obtained Lineweaver-Burk plot, the lines for the uninhibited enzyme and for the two different concentrations of sodium azide intersected to the left of the $1 / v_{0}$ axis and above the $1 /[S]$ axis, with a decrease in $V_{\max }$ and, conversely, an increase in $K_{\mathrm{m}}$, indicating that sodium azide exhibited mixed-type I inhibition for the oxidation of pyrocatechol by mushroom PPO.

The inhibitory kinetics of mushroom PPO by sodium azide are illustrated in Fig. (2). Mixed-type I inhibition implies that sodium azide affected the affinity of the enzyme for pyrocatechol but did not bind at the active site of the enzyme. As seen in Table 1 , a $K_{\mathrm{IS}} / K_{\mathrm{I}}$ ratio higher than 1 was obtained for sodium azide, indicating that the affinity of the inhibitor for free enzyme is stronger than that for the enzyme-substrate complex [25]. This behaviour suggests that this compound can bind both to free enzyme and to the enzyme-substrate complex, and that the equilibrium constants for these two interactions are different. In this case, mixed inhibition signifies that the inhibitor affects the affinity of the enzyme for its substrate, yet it does not bind at the active site for that substrate [26].

Gouzi and Benmansour [6] observed a competitive-type inhibition by sodium azide for triphenol oxidase activity of mushroom PPO, using pyrogallol as a substrate, with $K_{\mathrm{I}}$ value of $3.2 \mathrm{mM}$. Doğan, Turan, Doğan, Alkan and Arslan [27] observed non-competitive-type inhibition of Ocimum basilicum L. PPO by sodium azide when using pyrocatechol as a substrate.

Arslan and Doğan [5] found that sodium azide was a non-competitive inhibitor of artichoke and Ocimum basili- cum L. PPO when using pyrocatechol as a substrate. Furthermore, Aydemir, Kavrayan and Çinar [13] found that sodium azide acted as a competitive inhibitor of PPO extracted from Jerusalem artichoke (Helianthus tuberosus) when using pyrocatechol as substrate.

To date, azide has consistently been reported to act as an inhibitor of PPO. This behavior of azide is related to its ability to form complexes with many copper enzymes. Sodium azide's toxicity towards metal-containing enzymes, especially copper enzymes, is mainly due to its propensity to strongly coordinate the metal in the active site, which provokes changes in the coordination number and conformation of the active site $[28,29]$. The interaction between azide and copper ions in the active site may result in loss of the copper ions from the protein [15]. By preventing the ligation of the precursor tyrosine to the copper, azide inhibits the activity of the enzyme or competes for its active site with another reactive molecule, especially molecular oxygen [28].

As described above, the type of inhibition and the $K_{\mathrm{I}}$ value depend on the structures of both the substrate and the inhibitor [4]. The type of inhibition also depends on the origin of the studied PPO [30]. Hence, no general rule can easily be established with regard to the type of observed inhibition. The $K_{\mathrm{I}}$ and $K_{\mathrm{IS}}$ values depicted in Table 1 suggest that the most effective inhibitor of diphenol oxidase activity of mushroom PPO was benzoic acid, due to its $K_{\mathrm{I}}$ value. The fact that it is structurally analogous to substrates of PPO may explain its high inhibitory potency.

Benzoic acid and sodium azide are currently used in food technology, and may be useful in the prevention of enzymatic browning of mushroom products. In addition, the hazardous nature of sodium azide was also reported. Consequently, its use must be strictly controlled [31].

\section{Mixed-Type II Inhibition of Mushroom PPO Diphenol Oxidase Activity by Sodium Fluoride}

The mechanism whereby sodium fluoride inhibits the diphenol oxidase activity of mushroom PPO was investigated.

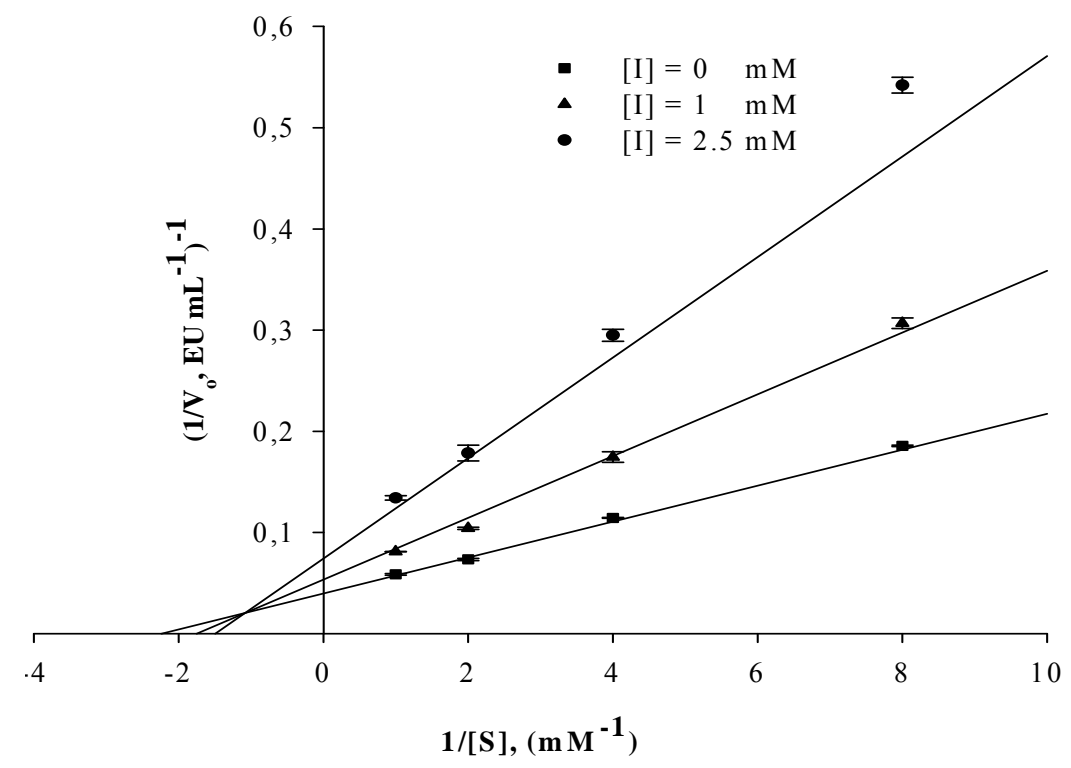

Fig. (2). Lineweaver-Burk plots for inhibition of PPO-mediated oxidation of pyrocatechol by sodium azide. The concentrations of sodium azide were $0(\bullet), 1(\boldsymbol{\Delta})$, and $2.5 \mathrm{mM}(\bullet)$. Each value is expressed as the mean \pm SE of three trials. 
The equilibrium constants for the inhibitor binding to free enzyme $(E), K_{\mathrm{I}}$, and to the enzyme-substrate $(E S)$ complex, $K_{\mathrm{IS}}$, are obtained from the second plots of the apparent $K_{\mathrm{m}} / V_{\max }$ and $1 / V_{\max }$, respectively, versus concentration of $(I)$. The inhibitory kinetics of mushroom PPO by sodium fluoride are illustrated in Fig. (3). Under the experimental conditions employed in this study, the oxidation reaction of pyrocatechol by mushroom PPO followed Michaelis-Menten kinetics.

Double-reciprocal plots yielded a family of straight lines intersecting in the $3^{\text {rd }}$ quadrant. Both $K_{\mathrm{m}}$ and $V_{\text {max }}$ decreased with increasing sodium fluoride concentration, which indicates that the inhibition was of the mixed-II type. The noncompetitive effect was stronger than the competitive effect, indicating that sodium fluoride inhibits the free enzyme more weakly than it inhibits the enzyme-substrate complex.

The $K_{\mathrm{I}}$ and $K_{\mathrm{IS}}$ inhibitory constants of sodium fluoride were 148.97 and $49.19 \mathrm{mM}$, respectively. These results are summarized in Table 1 . The value of $K_{\mathrm{I}}$ was greater than that of $K_{\mathrm{IS}}$, indicating that the affinity of the inhibitor for the enzyme-substrate complex was stronger than that for the free enzyme [9]. In terms of the inhibitory mechanism, the data suggest that sodium fluoride possibly binds not only to the free enzyme but also to the enzyme- substrate complex [32].

From these results, it can be hypothesized that the substrate binding site of the enzyme may be occupied by either the substrate or the inhibitor; however, we cannot exclude the possibility that there is a specific inhibitor binding site on PPO [33].

Gouzi and Benmansour [6] observed mixed-type I inhibition of mushroom PPO by sodium fluoride when using pyrogallol as a substrate.

\section{Effect of Benzoic Acid, Sodium Azide and Sodium Fluoride on Mushroom PPO Diphenolase Activity}

The effect of different concentrations of benzoic acid, sodium azide, and sodium fluoride on the oxidation of pyrocatechol by mushroom PPO was studied. Each of these in- hibitors showed a concentration-dependent inhibitory effect on PPO enzymatic activity.

Figs. (4-6) shows the percent inhibition of PPO by benzoic acid, sodium azide, and sodium fluoride, using pyrocatechol as a substrate. The enzymatic activity markedly decreased as the concentration of inhibitor increased.

In order to compare the inhibitory potencies of these various inhibitors, their $\mathrm{IC}_{50}$ values (defined as the concentration leading to $50 \%$ loss of activity) were determined under similar conditions. The obtained $\mathrm{IC}_{50}$ values are summarized in Table $\mathbf{1}$ for the purpose of comparison.

Of the three inhibitors tested, benzoic acid was the most potent with an $\mathrm{IC}_{50}$ of $0.147 \mathrm{mM}$. The second was sodium azide with an $\mathrm{IC}_{50}$ of $3.20 \mathrm{mM}$, and sodium fluoride was the weakest with an $\mathrm{IC}_{50}$ of $123.94 \mathrm{mM}$.

\section{CONCLUSION}

Inhibition of the diphenolase activity of Agaricus bisporus (J.E.Lange) PPO by various inhibitors is reported here for the first time. The results presented in this study indicate that the partially purified PPO obtained from Agaricus bisporus was effectively inhibited by various classical PPO inhibitors using pyrocatechol as substrate. The type of inhibition achieved by each inhibitor was dependent upon both the origin of the PPO and on the substrate.

Based on our results, the most potent inhibitor of mushroom PPO was benzoic acid, followed by sodium azide and then sodium fluoride. Benzoic acid was shown to compete with the substrate for binding to the active site of the enzyme. The $K_{\mathrm{IS}} / K_{\mathrm{I}}$ ratio obtained in this study was greater than that for sodium fluoride, indicating that the affinity of the inhibitor for the free enzyme was stronger than that for the enzyme-substrate complex.

Use of benzoic acid and sodium azide may effectively prevent the enzymatic browning of Agaricus bisporus during storage, since both compounds inhibit mushroom PPO activity at very low concentrations.

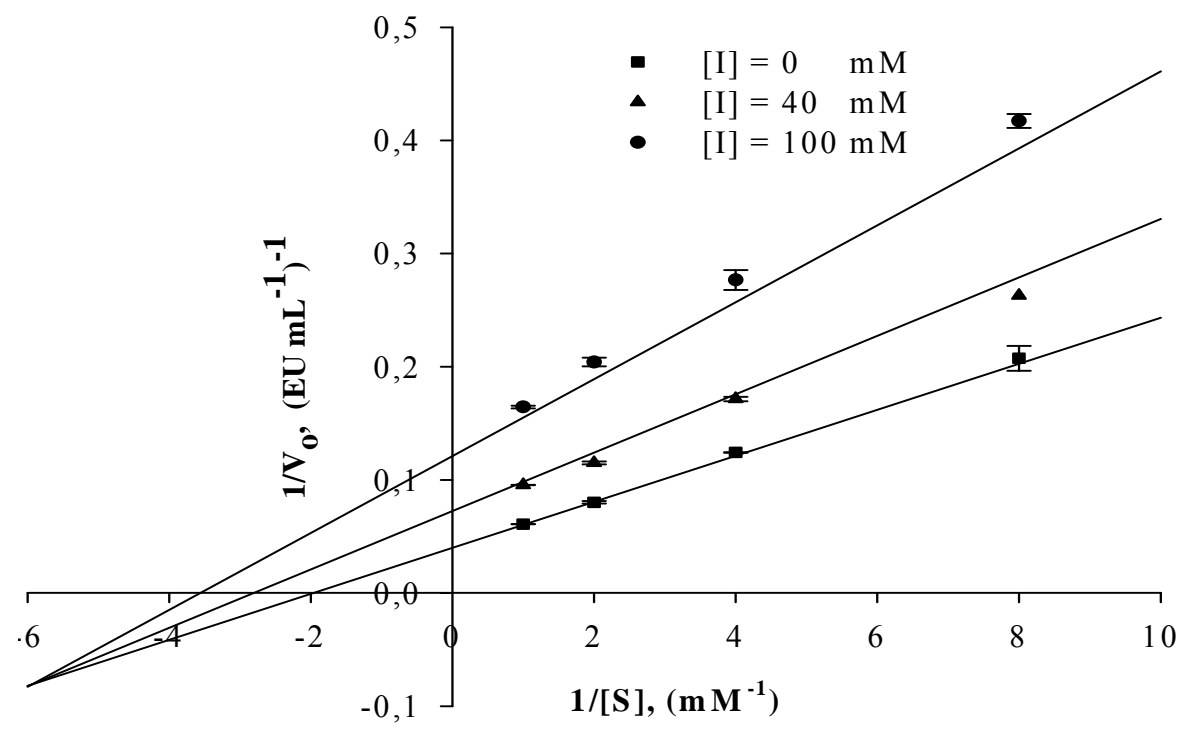

Fig. (3). Lineweaver-Burk plots for the inhibition of PPO-mediated oxidation of pyrocatechol by sodium fluoride. The concentrations of sodium fluoride were $0(\boldsymbol{\bullet}), 40(\boldsymbol{\Delta})$, and $100 \mathrm{mM}(\bullet)$. Each value is expressed as the mean $\pm \mathrm{SE}$ of three trials. 


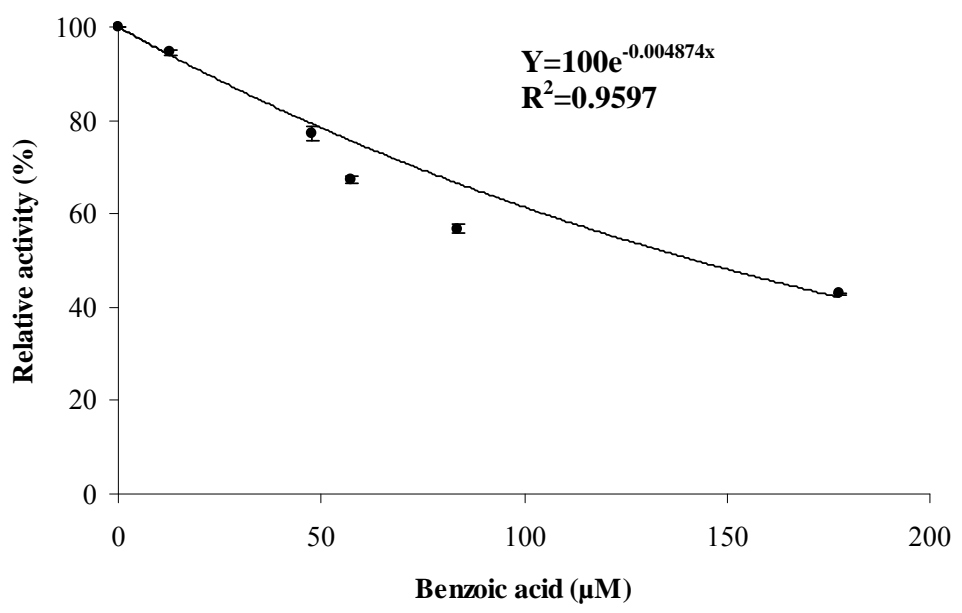

Fig. (4). Benzoic acid-mediated inhibition of mushroom PPO diphenolase activity as reflected by the oxidation of pyrocatechol at $25^{\circ} \mathrm{C}$. Assay conditions: $2.0 \mathrm{ml}$ reactions systems contained $0.1 \mathrm{M} \mathrm{K}_{2} \mathrm{HPO}_{4}-\mathrm{KH}_{2} \mathrm{PO}_{4}$ buffer $(\mathrm{pH} 7.0$ ), $0.4 \mathrm{mM}$ pyrocatechol, and $10 \mu \mathrm{lof}$ mushroom $\mathrm{PPO}$. Each value is expressed as the mean $\pm \mathrm{SE}$ of three trials.

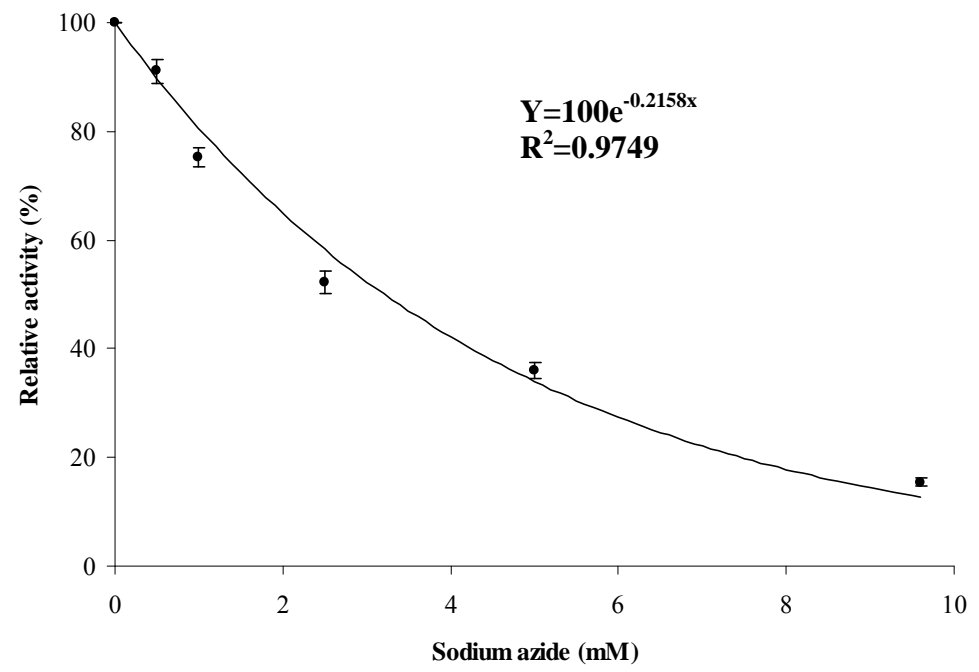

Fig. (5). Sodium azide-mediated inhibition of mushroom PPO diphenolase activity as reflected by the oxidation of pyrocatechol at $25^{\circ} \mathrm{C}$. Assay conditions: $2.0 \mathrm{ml}$ reactions systems contained $0.1 \mathrm{M} \mathrm{K}_{2} \mathrm{HPO}_{4}-\mathrm{KH}_{2} \mathrm{PO}_{4}$ buffer (pH 7.0), $0.4 \mathrm{mM}$ pyrocatechol, and $10 \mu 1$ of mushroom $\mathrm{PPO}$. Each value is expressed as the mean $\pm \mathrm{SE}$ of three trials.

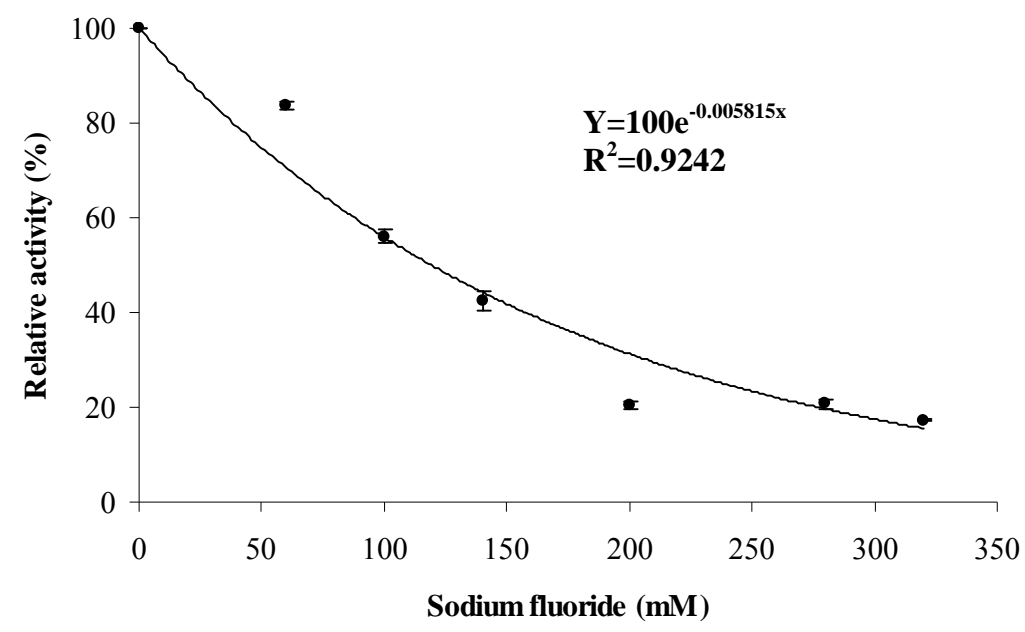

Fig. (6). Sodium fluoride-mediated inhibition of mushroom PPO diphenolase activity as reflected by the oxidation of pyrocatechol at $25^{\circ} \mathrm{C}$. Assay conditions: $2.0 \mathrm{ml}$ reactions systems contained $0.1 \mathrm{M} \mathrm{K}_{2} \mathrm{HPO}_{4}-\mathrm{KH}_{2} \mathrm{PO}_{4}$ buffer ( $\mathrm{pH} 7.0$ ), $0.4 \mathrm{mM}$ pyrocatechol, and $10 \mu 1$ of mushroom $\mathrm{PPO}$. Each value is expressed as the mean $\pm \mathrm{SE}$ of three trials. 


\section{ACKNOWLEDGEMENTS}

We warmly thank Professors Armando Gómez Puyou (Universidad Nacional Autónoma de México, 04510 México, D. F., México), William H. Flurkey (Indiana State University, Terre Haute, Indiana 47809) and Amine AZIZ (University of Hassan II-Mohammedia, 20650 Mohammadia, Morocco) for their contribution to the work presented here. We also thank the reviewers for their constructive comments.

\section{REFERENCES}

[1] Jolivet S, Arpin N, Wichers HJ, Pellon G. Agaricus bisporus browning: a review. Mycol Res 1998; 102: 1459-83.

[2] Martinez MV, Whitaker JR. The biochemistry and control of enzymatic browning. Trends Food Sci Technol 1995; 6: 195-200.

[3] Sánchez-Ferrer A, Rodríguez-López JN, García-Canovas F, García-Carmona F. Tyrosinase: a comprehensive review of its mechanism. Biochim Bio Phys Acta 1995; 1247: 1-11.

[4] Vámos-Vigyázó L. Polyphenol oxidase and peroxidase in fruits and vegetables. CRC Crit Rev Food Sci Nutr 1981; 15: 49-127.

[5] Arslan O, Doğan S. Inhibition of polyphenol oxidase obtained from various sources by 2,3-diaminopropionic acid. J Sci Food 2005; 85: 1499-504.

[6] Gouzi H, Benmansour A. Partial purification and characterization of polyphenol oxidase extracted from Agaricus bisporus (J.E. Lange) Imbach. Int J Chem React Eng 2007; 5: 1-11.

[7] Kahn V, Ben-Shalom N, Zakin V. Effect of benzenesulfinic acid on the oxidation of o-dihydroxy- and trihydroxyphenols by mushroom tyrosinase. J Food Biochem 1999; 23: 263-81.

[8] Qiu L, Chen QH, Zhuang JX, et al. Inhibitory effects of $\alpha$-cyano-4hydroxycinnamic acid on the activity of mushroom tyrosinase. Food Chem 2009; 112: 609-13.

[9] Han P, Chen CQ, Zhang CL, Song KK, Zhou HT, Chen QX. Inhibitory effects of 4-chlorosalicylic acid on mushroom tyrosinase and its antimicrobial activities. Food Chem 2008; 107: 797-803.

[10] Likhitwitayawuid K. Stilbenes with tyrosinase inhibitory activity. Curr Sci 2008; 94: 44-52.

[11] Burton SG. Biocatalysis with polyphenol oxidase: a review. Catal Today 1994; 22: 459-87.

[12] Parvez S, Kang M, Chung HS, Bae H. Naturally occurring tyrosinase inhibitors: mechanism and applications in skin health, cosmetics and agriculture industries. Phytother Res 2007; 21: 80516 .

[13] Aydemir T, Kavrayan D, Çinar S. Isolation and characterisation of polyphenoloxidase from Jerusalem artichoke (Helianthus tuberosus) Sayi 2003; 21: 115-25.

[14] Kouakou TH, Kouadio YJ, Kouamé P, Waffo-Téguo P, Décendit A, Mérillon J-M. Purification and biochemical characterization of polyphenol oxidases from embryogenic and nonembryogenic cotton (Gossypium hirsutum L.) cells. Appl Biochem Biotechnol 2009; 158: 285-301.

[15] Gao ZJ, Han XH, Xiao XG. Purification and characterisation of polyphenol oxidase from red Swiss chard (Beta vulgaris subspecies cicla) leaves. Food Chem 2009; 117: 342-8.
[16] Mayer AM, Harel E. Review: polyphenol oxidases in plants. Phytochemistry 1979; 18: 193-215.

[17] Zawistowski J, Biliaderis CG, Michael NA. Polyphenol oxidase. In: Robinson DS, Eskin NAM, Eds.; Oxidative Enzyme in Foods.; London, UK, Publisher: Elsevier Applied Science Ltd 1991; pp. 217-73.

[18] Rescigno A, Sollai F, Pisu B, Rinaldi A, Sanjust E. Tyrosinase inhibition: General and applied aspects. J Enzyme Inhibit Med Chem 2002; 17: 207-18.

[19] Baurin N, Arnoult E, Scior T, Do QT, Bernard P. Preliminary screening of some tropical plants for anti-tyrosinase activity. J Ethnopharmacol 2002; 82: 155-8.

[20] Fan Y, Flurkey WH. Purification and characterization of tyrosinase from gill tissue of Portabella mushrooms. Phytochemistry 2004; 65: 671-8.

[21] Chen QX, Lu HY, Zhu CM, Lin HN, Zhou HM. The effect of Nthiophosphoryl amino acids on the activity of green crab (Scylla serrata) alkaline phosphatase. Biochem Mol Biol Int 1998; 45: 465-73.

[22] Doğan S, Turan Y, Ertürk H, Arslan O. Characterization and Purification of Polyphenol Oxidase from Artichoke (Cynara scolymus L.). J Agric Food Chem 2005; 53: 776-85.

[23] Pifferi PG, Baldassari L, Cultrera R. Inhibition by carboxylic acids of an o-diphenol oxidase from Prunus avium fruits. J Sci Food Agric 1974; 25: 263-70.

[24] Duckworth HW, Coleman JE. Physicochemical and kinetic properties of mushroom tyrosinase. J Biol Chem 1970; 245: 161325 .

[25] Bar M. Kinetics and physico-chemical properties of white-rot fungal laccases. Magister scientiae. diss., Department of Microbiology and Biochemistry In the Faculty of Natural and Agricultural Science, University of the Free State: Bloemfontein 2001.

[26] Macrae AR, Duggleby RG. Substrates and inhibitors of potato tuber phenolase. Phytochemistry 1968; 7: 855-61.

[27] Doğan S, Turan P, Doğan M, Alkan M, Arslan O. Inhibition Kinetic of Ocimum basilicum L. Polyphenol Oxidase. Int J Chem React Eng 2007; 5: 1-12

[28] Shi C, Liu Q, Dai Y, Xie Y, Xu X. The mechanism of azide activation of polyphenol oxidase II from tobacco. Acta Biochim Polon 2002; 49: 1029-35.

[29] Gundoğmaz G, Doğan S, Arslan O. Some kinetic properties of polyphenol oxidase obtained from various salvia species (Salvia viridis L., Salvia virgata Jacq. and Salvia tomentosa Miller). Food Sci Technol Int 2003; 9: 308-15.

[30] Robert C, Rouch C, Cadet F. Inhibition of palmito (Acanthophoenix rubra) polyphenol oxidase by carboxylic acids. Food Chem 1997; 59: 355-60.

[31] Yağar H, Sağiroğlu A. Partially purification and characterization of polyphenol oxidase of quince. Turkish J Chem 2002; 26: 97104.

[32] Song KK, Lin JF, Chen QX. Inhibitory effects of 4-isopropylsalicylaldehyde on mushroom tyrosinase. Food Chem 2005; doi: 10.1016/j.foodchem. 2005.08.021.

[33] Walker JRL, Wilson EL. Studies on the enzymatic browning of apples. Inhibition of apple o-diphenol oxidase by phenolic acids. J Sci Food Agric 1975; 26: 1825-31. 